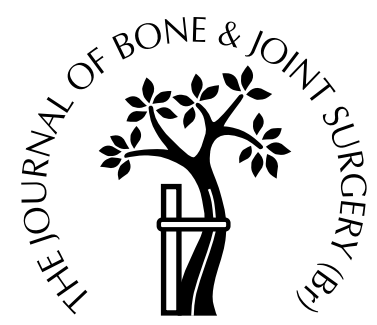

\title{
Low-friction arthroplasty of the hip using alumina ceramic and cross-linked polyethylene
}

\author{
A TEN-YEAR FOLLOW-UP REPORT \\ B. M. Wroblewski, P. D. Siney, P. A. Fleming \\ From Wrightington Hospital, Wigan, England
}

W e report the results of our continued review of 14 hip arthroplasties using alumina ceramic femoral heads with cross-linked polyethylene cups.

There have been no complications and a very low rate of penetration. This was $0.02 \mathrm{~mm}$ per year after an initial 'bedding-in' period of two years. There has been no change in the mean rate between our earlier study at six years and the current results at 10 to 11 years.

The use of these bearing surfaces appears to reduce the potential amount of polyethylene debris and may provide the next logical stage in the development of the Charnley low-friction arthroplasty.

J Bone Joint Surg [Br] 1999;81-B:54-5.

Received 10 February 1998; Accepted after revision 2 April 1998

In 1996 we described a simulator study of the wear of crosslinked polyethylene (XLP) cups articulating with $22.225 \mathrm{~mm}$ alumina ceramic heads, ${ }^{1}$ and the radiological measurements of penetration in 19 of these hip replacements in 17 patients at a follow-up to 77 months. The simulator study showed a relatively high penetration of nearly $0.2 \mathrm{~mm}$ after 1.5 million cycles, the equivalent of the first 18 months of clinical use, but only about $0.1 \mathrm{~mm}$ during an additional 4.8 million cycles after the bedding-in period. In the clinical series, the radiological penetration was 0.2 to $0.4 \mathrm{~mm}$ (mean 0.29) during this initial period, but the subsequent mean rate after bedding-in was $0.022 \mathrm{~mm} /$ year.

We have now followed up the same group of patients for a mean of over ten years.

B. M. Wroblewski, FRCS, Consultant Orthopaedic Surgeon, Professor of Orthopaedic Biomechanics

P. D. Siney, BA, Research Fellow

P. A. Fleming, Research Assistant

The John Charnley Research Institute, Wrightington Hospital for Joint

Disease, Hall Lane, Appley Bridge, Wigan, Lancashire WN6 9EP, UK.

Correspondence should be sent to Professor B. M. Wroblewski.

(C)1999 British Editorial Society of Bone and Joint Surgery 0301-620X/99/18822 \$2.00

\section{Patients and Methods}

Of the original 17 patients, ${ }^{1} 12$ were men and five were women. Two men had had bilateral arthroplasties. Their mean age at operation was 53 years (27 to 80$)$ and their mean weight was $76 \mathrm{~kg}$ (54 to 102). Four patients have died and one, who is confined to a wheelchair because of multiple sclerosis, has not been studied. The other 12 patients with 14 ceramic XLP arthroplasties remain under review with regular radiographs.

Penetration was measured from standard pelvic radiographs, centred on the symphysis pubis, as the apparent shortest distance between the head and a marker wire in the cup, which was carefully aligned in the coronal plane at insertion. This method has previously been described by Griffith and others ${ }_{3}^{2}$ and verified by comparison with retrieved specimens.

\section{Results}

A total of 14 ceramic XLP hips in 12 patients has now been followed for over ten years. None has needed revision, there have been no problems related to the design, and all the patients have continued physical activities appropriate to their age and gender. The mean total penetration at 10 years to 11 years 3 months is $0.37 \mathrm{~mm}$ ( 0.2 to 0.41$)$, giving

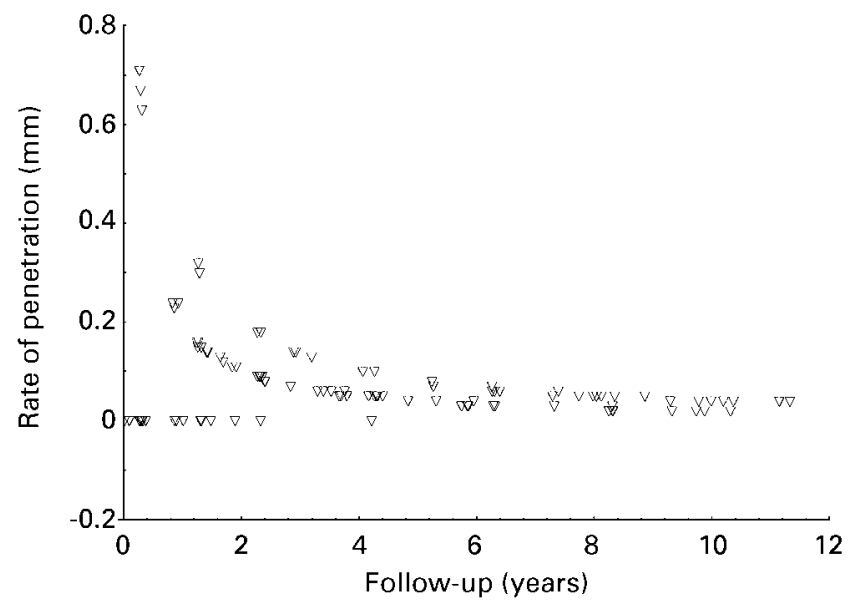

Fig. 1

Calculated rate of penetration of intervals related to duration of follow-up. 
Table I. Comparison of the rate of penetration in four patients with bilateral arthroplasties, one of alumina ceramic and cross-linked polyethylene and the other of stainless steel and UHMWPE

\begin{tabular}{|c|c|c|c|c|c|c|c|c|c|}
\hline \multirow[b]{3}{*}{ Case } & \multirow[b]{3}{*}{ Gender } & \multicolumn{4}{|c|}{ Alumina ceramic XLP } & \multicolumn{4}{|c|}{ Stainless steel on UHMWPE } \\
\hline & & \multicolumn{2}{|c|}{ Follow-up } & \multicolumn{2}{|l|}{ Penetration } & \multicolumn{2}{|c|}{ Follow-up } & \multicolumn{2}{|l|}{ Penetration } \\
\hline & & Yr & Mth & Total (mm) & Rate $(\mathrm{mm} / \mathbf{y r})$ & Yr & Mth & Total (mm) & Rate $(\mathbf{m m} / \mathbf{y r})$ \\
\hline 1 & Male & 10 & 3 & 0.2 & 0.02 & 10 & 3 & 1.6 & 0.16 \\
\hline 2 & Male & 10 & 2 & 0.4 & 0.04 & 11 & 2 & 3.2 & 0.29 \\
\hline 3 & Male & 11 & 4 & 0.4 & 0.04 & 16 & 2 & 1.2 & 0.08 \\
\hline 4 & Female & 4 & 0 & 0.39 & 0.1 & 2 & 1 & 0.4 & 0.2 \\
\hline
\end{tabular}

a mean rate of $0.037 \mathrm{~mm} / \mathrm{year}$. This overall rate has remained unchanged since our previous paper.

Initially, we found a high penetration of up to $0.7 \mathrm{~mm}$ in the first year. The mean rate of $0.22 \mathrm{~mm}$ per year $(0$ to 0.41$)$ in the first two years fell to a mean of $0.02 \mathrm{~mm}$ in the third and subsequent years, and this has continued to a mean follow-up of 10 years 6 months, as shown in Figure 1.

Four of the index patients also had conventional stainlesssteel on ultra-high-molecular-weight polyethylene (UHMWPE) hip replacements on the contralateral side. The results for penetration in these paired hips is shown in Table I: the mean penetration in these patients was $0.04 \mathrm{~mm}$ per year for ceramic XLP replacements and four times greater at $0.16 \mathrm{~mm}$ per year for the conventional hips.

\section{Discussion}

After the first two years with a mean rate of penetration of $0.11 \mathrm{~mm}$ per year (0 to 0.22 ), the subsequent rate for the ceramic XLP replacements has remained the same for eight years, at $0.02 \mathrm{~mm}$ per year (0 to 0.05 ).

A recent large series of stainless-steel UHMWPE hips in patients under 51 years of age ${ }^{4}$ showed a mean penetration rate of $0.11 \mathrm{~mm}$ per year, which is considerably greater, even allowing for the different age group. Compared with this series, the ceramic XLP combination offers a fivefold reduction in the rate of penetration. Whether or not polyethylene wear particles play a part in the loosening of components remains to be addressed. There is little doubt that reducing rates of wear by the use of a ceramic polyethylene combination is the next stage of evolution of the Charnley LFA. There have been no problems that could be attributed to the design used in this report.

This was supported by The Peter Kershaw and the John Charnley Trust. No benefits in any form have been received or will be received from a commercial party related directly or indirectly to the subject of this article.

\section{References}

1. Wroblewski BM, Siney PD, Dowson D, Collins SN. Prospective clinical and joint simulator studies of a new total hip arthroplasty using alumina ceramic heads and cross-linked polyethylene cups. $J$ Bone Joint Surg [Br] 1996;78-B:280-5.

2. Griffith MJ, Seidenstein MK, Williams D, Charnley J. Socket wear in Charnley low friction arthroplasty of the hip. Clin Orthop 1978; $137: 37-47$

3. Wroblewski BM. Direction and weight of socket wear in Charnley low-friction arthroplasty. J Bone Joint Surg [Br] 1985;67-B:757-61.

4. Wroblewski BM, Siney PD. Charnley low friction arthroplasty in the young patient. Clin Orthop 1992;285:45-7. 